\title{
DESIGN OF PEDESTAL FOR MOUNTING OF HYDRAULIC GRAPPLE ON SKIDDER
}

\author{
Jan Dizo, Miroslav Blatnicky, Filip Fidrik \\ University of Zilina, Slovakia \\ jan.dizo@fstroj.uniza.sk,miroslav.blatnicky@fstroj.uniza.sk
}

\begin{abstract}
Skidders represent an important part of the forestry. They allow to perform timber harvesting in difficult conditions of forests in an effective way. In the Slovak republic, only one company currently produces several types of articulated steering skidders differing by the dimensions, operating weight, engine power etc., which are well-known and used in the region of central and Eastern Europe for many years. These products are exposed to the strong competition from other world producers. In comparison with earlier technical solution of skidders, which have used winches for pulling trees to a landing, skidders are recently most often equipped with a hydraulic grapple, which is controlled by an operator directly from a skidder cabin. Thus, the operator has not to get off the cabin in order to drag the cable to the logs and hook them up. Hence, the hydraulic grapple improves the user comfort of a skidder, mainly in bad weather conditions. Therefore, every skidder is currently required to allow mounting the hydraulic grapple. The content of this article is focused on presentation of the design of a pedestal, which is intended to be mounted on an articulated steering skidder. The pedestal is the structural unit of the smallest type of the skidders produced in the Slovak Republic. The designed pedestal will be mounted in the rear part of the skidder. Winches are located under it. Therefore, the pedestal has to be clapper for better access to winches during maintenance and repair processes. As the pedestal will be loaded by various types of loads resulting from its fundamentals in the real operating conditions, its structure has to be designed precisely. The article contains a CAD model of the pedestal. Based on the calculated forces, which will act on it during a real operation, strength analyses are carried out.
\end{abstract}

Keywords: tractor, pedestal, CAD model, strength analyses.

\section{Introduction}

Consistent technological progress in the field of machine industry has caused significant increase of using special logging tractors (or skidders) for timber harvesting and yarding [1;2]. Nowadays, yarding by means of logging tractors is the most widely used way for timber harvesting in forests not only in Europe, but also around the world [3; 4]. Technologies applied in these special wheeled forest tractors allow to use them in every type of terrain, as well as in various gradient of slopes. Recent needs of customers require to design a new and more compact model of a tractor, which would be able to compete with other products in the European market.

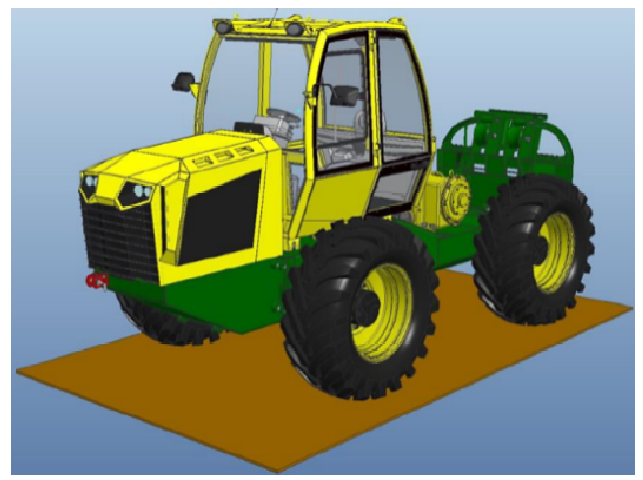

Fig. 1. Three-dimensional model of the solved tractor

The objective of the presented article is an engineering design of a pedestal, which will serve for mounting of a hydraulic arm on the newest and the smallest size tractor. This model represents the logging tractor, which belongs to the smallest tractors in this sector within the European market. The presented solution has arisen due to the need of mounting of a hydraulic arm on the given tractor as non-standard equipment.

Timber logging can be defined as transposition of logs form a place of harvesting to a place of timber processing or timber transportation. Ground yarding is most often used for slopes up to $40 \%$, but some logging tractors are able to work on slopes even up to $50 \%[1-4]$. 


\section{Materials and methods}

The engineering design of a pedestal is developed from the analysis of the structure of the tractor, on which it will be mounted. For this purpose, analytical methods were used. Further, the structure has been analysed in terms of strength. These analyses have been carried out by means of the finite element method. A winch and a hydraulic arm with a grapple are very important construction units of the solved tractor. The main role of the winch (Fig. 2) is yarding of logs from hardly accessible places nearer to the tractor. The two-drum winch optionally controlled by means of a remote control is mounted on the rear part of the tractor frame and it is included in a base package of the tractor. When logs are near enough the tractor, an operator can handle the logs by means of the hydraulic arm (Fig. 3). This hydraulic arm will be mounted on the pedestal, which is placed above the winch, whereby operational space of the winch, as well as the hydraulic arm must not be limited. Just this component is the objective of the solved task.

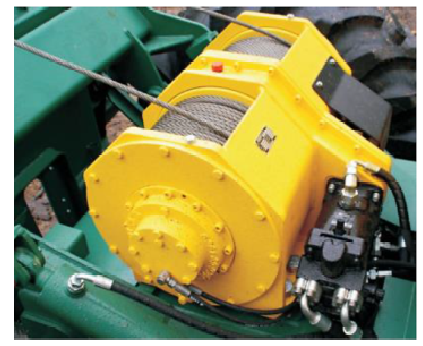

Fig. 2. Two-drum winch

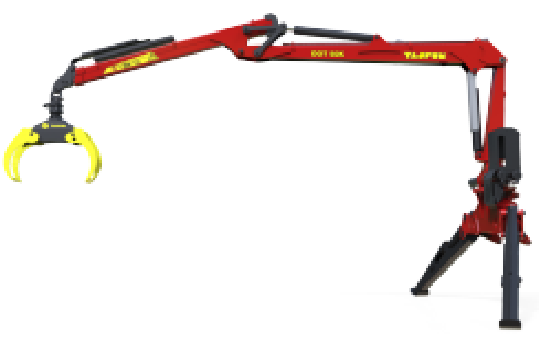

Fig. 3. View of a selected hydraulic arm

Hydraulic arms of logging tractors are mostly placed in the rear part of the tractor frame. Such a conception allows utility of tractors, mainly in a hardly accessible terrain and in bad weather conditions. The solved logging tractor is intended for using in thinning and premature timber harvesting and for easier yarding of toppled trees and other wood-pulps.

In terms of the conception, it is a four-wheeled articulated tractor with an all-wheel drive train. A steering system of the tractor contains two hydromotors and vertical pins [5]. Such a system ensures very well manoeuvrability and ability to work in heavy gradient of slopes. The tractor is powered by a four-cylinder four-stroke diesel engine, which is liquid-cooled and turbocharged by a supercharger. The engine meets all valid limits in terms of exhaust emission regulations for ensuring ecological operation [6].

Selection of the hydraulic arm results from two terms. On the one hand, criterion assessment of various available products has been performed, and on the other, requirements of the tractor producer have been taken into account. Figure 4 shows a working range of the selected hydraulic arm and a traffic flow diagram of the selected hydraulic arm is shown in Fig. 5.

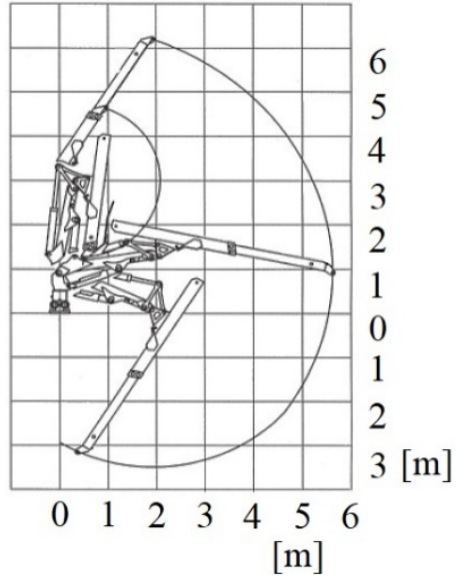

Fig. 4. Working range of the hydraulic arm

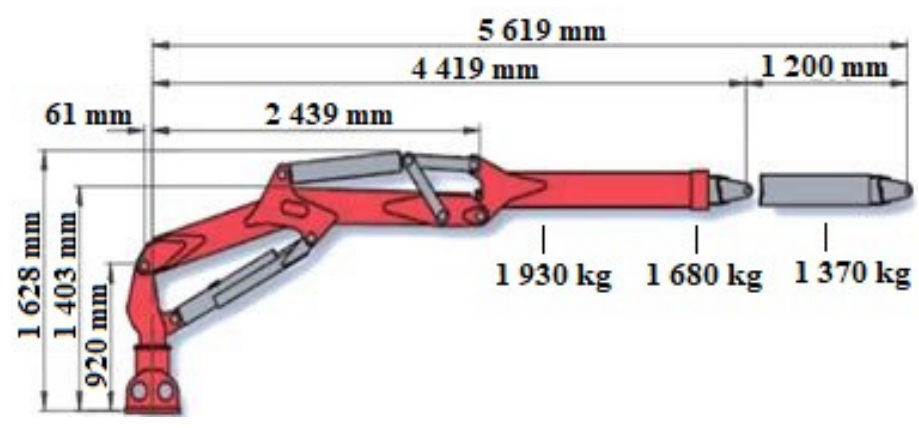

Fig. 5. Traffic flow diagram of the hydraulic arm 
The hydraulic arm is located on the tractor by means of an adapted pedestal, which is placed above the winch. The hydraulic arm is mounted on the pedestal by ten screws with a cylindrical head and with an internal hexagon. As the hydraulic arm is nonstandard equipment of the tractor, it is necessary to design such a pedestal structure, which can be installed and removed in a simple way, which will not be time-consuming.

When the pedestal is designed, it is necessary to take into account the fact that in it the winch is located. Therefore, in case of its failure, it is needed to ensure an adequate sea-room for repairing the winch or changing drums. These service acts have to be allowed without removal of the pedestal including the hydraulic arm. These requirements have resulted in the technical solution based on using two pins, which allow to lift off the pedestal. The position of pins is displayed by red circles in Fig. 6 .

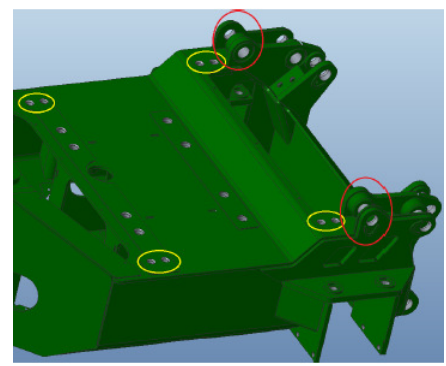

Fig. 6. Rear part of the tractor for mounting the pedestal

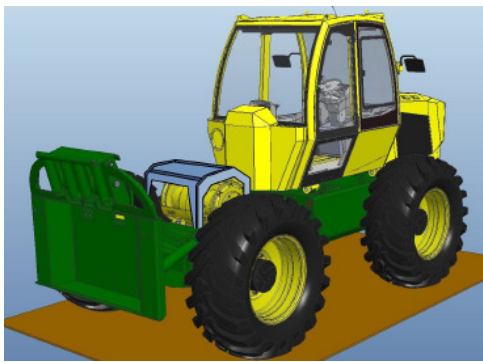

Fig. 7. Designed pedestal mounded on the rear part of the tractor frame

The rear part of the tractor is adapted for mounting the pedestal. Yellow circles displayed in Fig. 6 show locations, where the pedestal in mounted on the rear part of frame. The mutual position of the pedestal and the tractor frame is shown in Fig. 7. As we can see, the pedestal, i. e. the hydraulic arm, is located behind the cabin. The operator will see a wide working range of the hydraulic arm through a large window. Figure 8 shows the pedestal with items.
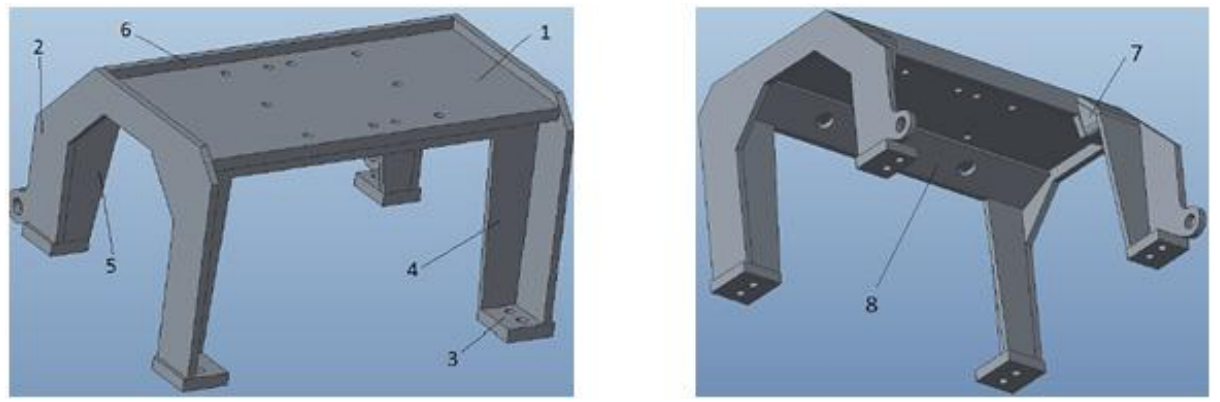

Fig. 8. Pedestal design

A base plate with thickness of $35 \mathrm{~mm}$ (1) is the main structural part of the pedestal. Ten holes with a tread of M24 are cut in it. This plate is welded by fillet welds with side walls (2), in which eyes are created. The eyes serve as hinges for folding up the pedestal including the hydraulic arm. The side wall thickness is $20 \mathrm{~mm}$. The pedestal will be placed on the rear frame by means of four feet (3) with thickness of $30 \mathrm{~mm}$. Every foot includes two holes with a diameter of $25 \mathrm{~mm}$. The pedestal structure is stiffened by the front wall (4), by rear stiffeners $(5,6)$, as well as additional two other stiffeners $(7,8)$. The thickness of the stiffeners is $15 \mathrm{~mm}$. Due to the requirements in terms of stiffness and minimal deformations, the pedestal is made as a weldment. Welding joints ensure durable and long-live joint. Consideration several factors, S355J0 steel has been chosen as the suitable material for the pedestal construction.

As the hydraulic arm and the pedestal are mounted on the rear frame by means of screws M24x65, the analysis of the screw connection has to be performed. The screw is analysed in terms of the tensile stress. The maximal permissible tensile stress depends on the yield strength and the safety coefficient. It is given as follows:

$$
\sigma_{p e r} \leq k_{S} \cdot \sigma_{R e},
$$


where $\sigma_{p e r}$ - maximal permissible tensile stress, $\mathrm{MPa}$;

$\sigma_{R e}$ - yield strength, MPa;

$k_{S}$ - safety coefficient of a screw.

When we consider the yield strength of the used steel of $1080 \mathrm{MPa}$ [7] and the safety coefficient of 0.8 , the equation (1) results to the following value of $\sigma_{p e r}=864 \mathrm{MPa}$.

The maximal axial force, which the chosen screw is able to transmit, is given in the machine tables. For the screw M24, the maximal axial force is $258928 \mathrm{~N}$. Further, the cross section of the screw core is $353 \mathrm{~mm}^{2}$. Considering the maximal axial force and the cross section of the screw core, we can calculate the maximal tensile stress in the screw, which is compared with the maximal permissible tensile stress given by equation (1). The maximal tensile stress is determined as follows:

$$
\sigma_{\text {Tmax }}=\frac{F_{\max }}{S_{S C}}=\frac{258928}{353}=733.5 \mathrm{MPa},
$$

where $\sigma_{T \max }-$ maximal tensile stress in the screw, MPa;

$F_{\max }$ - maximal axial force in the screw, $\mathrm{N}$;

$S_{S C}-$ cross section of the screw core, $\mathrm{mm}^{2}$.

When we compare the maximal permissible tensile stress (eq. 1) and the maximal tensile stress in the screw (eq. 2), the chosen screw meets the strength conditions and it is suitable for mounting the pedestal.

Moreover, we have to analyse the screw in terms of the pressure in a thread. For the S355J0 steel, which is used for the base plate with thickness of $35 \mathrm{~mm}$ (Fig. 8, item 1), the maximal permissible value of the pressure in threads is given by:

$$
p_{p e r}=0.8 \cdot \sigma_{p e r 355},
$$

where $p_{p e r}$ - maximal permissible pressure in the thread, MPa; $\sigma_{\text {per355 }}$ - maximal permissible tensile strength of the S355J0 steel, MPa.

The maximal permissible tensile strength of the S355J0 steel is calculated based on its yield of strength and the safety coefficient as follows:

$$
\sigma_{\text {per355 }}=\frac{\sigma_{R e 355}}{k},
$$

where $\sigma_{R e 355}-$ yield of strength of the S355J0 steel, MPa;

$F_{\max }$ - maximal axial force in the screw, $\mathrm{N}$;

$k_{S}$ - safety coefficient.

If we consider that the yield of the strength of the S355J0 steel is $\sigma_{R e 355}=355 \mathrm{MPa}$ [7] and the safety coefficient is $k=2$, the maximal permissible tensile strength results from eq. 4 and it is $\sigma_{\text {per } 355}=177.5 \mathrm{MPa}$, and the maximal permissible pressure in threads results from eq. 3 and it is $p_{p e r}=142 \mathrm{MPa}$.

For calculation of the pressure in a thread, the number of threads is given by the following formulation:

$$
z=\frac{b}{P}
$$

where $z$ - number of threads;

$b$ - length of the screw thread, mm;

$P$ - thread pitch, mm.

When we substitute the needed length of the screw $b=60 \mathrm{~mm}$ and the thread pitch $P=3 \mathrm{~mm}$ in eq. 6 , the screw has to have 20 threads. The pressure in threads is determined as:

$$
p_{T}=\frac{F_{\max }}{\frac{\pi}{4} \cdot\left(D^{2}-d^{2}\right) \cdot z},
$$


where $p_{T}$ - pressure in threads, $\mathrm{MPa}$;

$D$ - crest diameter of the screw, mm;

$d$ - root diameter of the screw, $\mathrm{mm}$.

The crest diameter and the root diameter of the considered screw are $D=24 \mathrm{~mm}$ and $d=21.252 \mathrm{~mm}$, respectively. After substituting known values, the pressure in threads is $p_{T}=132.56 \mathrm{MPa}$. Comparing this calculated value with the value of the permissible pressure in treads, we observe that the screw is suitable for mounting the pedestal.

\section{Results and discussion}

This section contains results of numerical analyses of the designed pedestal structure. Strength analyses have been carried out in the ANSYS software package, which is one of the most widely used software for numerical analysis of technical elements and systems based on the finite element method [8-10]. These analyses serve as a decisive criterion of the pedestal design. The pedestal geometry has been created in the PTC Creo Parametric 2.0 program. Subsequently, the geometry was modified according to the FE program needs. A mesh model of the pedestal is shown in Fig. 9. The most appropriate mesh consisted of tetrahedral elements with the size of $5 \mathrm{~mm}$.

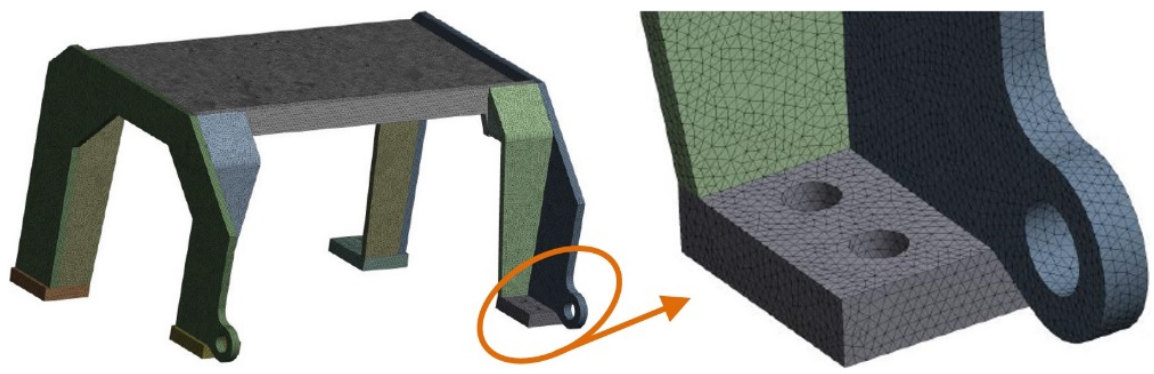

Fig. 9. Mash model of the pedestal

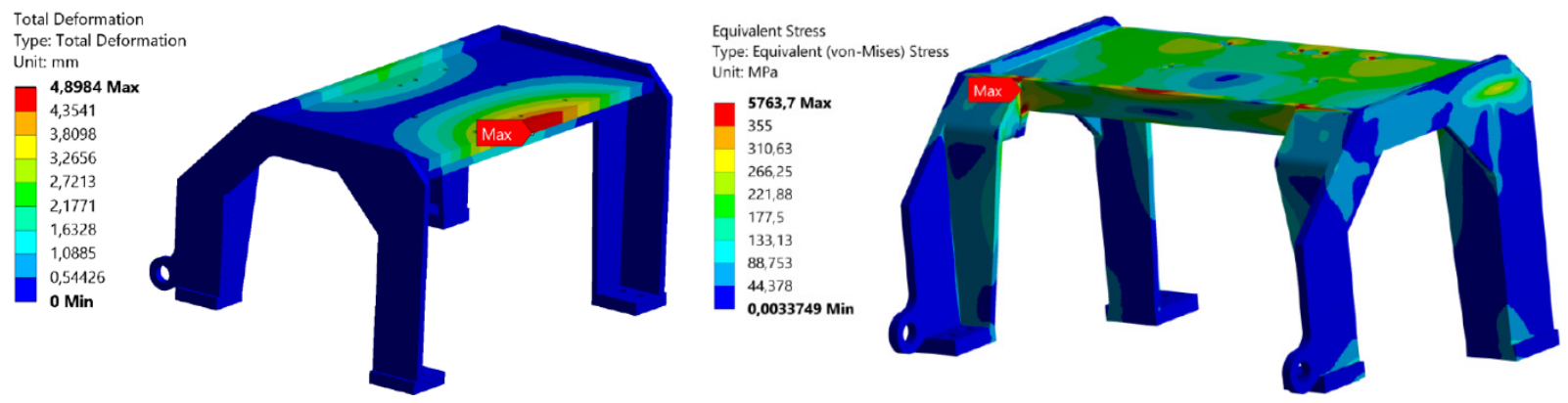

Fig. 10. Total deformation of the pedestal

Fig. 11. Distribution of the von Misses stress in the pedestal

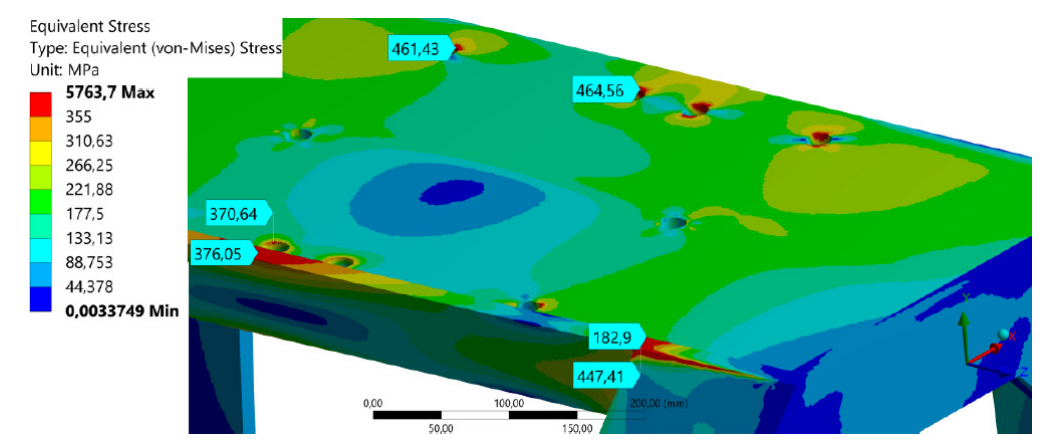

Fig. 12. Details of the stress distribution in the upper part of the pedestal

The boundary conditions include definition of couplings in locations, where the pedestal is mounted on the tractor frame by means of screws. Acting forces have been defined in locations, where the hydraulic arm is coupled with the pedestal. Figure 10 shows, that the upper base plate is the most deformed part of the pedestal. It is deformed in the front part. The value of the maximal displacement 
is $4.898 \mathrm{~mm}$. The results of distribution of the stress calculated according to the von Misses hypothesis are shown in Fig. 11. The greatest values of stress are up to $5763.7 \mathrm{MPa}$. However, these results are not adequate. It is an error, which does not correspond to the distribution of stress, because the values of stress detected near to this extreme value are much smaller. Therefore, this extreme value can be neglected. Figure 12 shows details of distribution of the stress in the upper plate. The greatest values are identified in the areas of holes for screws and in the location of the front stiffener, which reach the values to $464 \mathrm{MPa}$. Although these values are higher than the yield of the strength of the used material, they are detected only locally in narrow areas of holes. The rest of the structure meets the given demands in terms of strength.

\section{Conclusions}

1. The article presents the design of a pedestal for the hydraulic arm, which is intended to be mounted on a logging tractor.

2. From the strength point of view, the pedestal structure meets given requirements.

3. Further research in this filed will be aimed at creation of a multibody model of the logging tractor, which will serve to perform dynamic analyses of the tractor for assessment its stability during moving in various terrains.

\section{Acknowledgements}

This work was supported by the Cultural and Educational Grant Agency of the Ministry of Education of the Slovak Republic in the project No. KEGA 023ŽU-4/2020: Development of advanced virtual models for studying and investigation of transport means operation characteristics.

\section{References}

[1] Kašpárek J., Skopán M., Sedláček M. The development of the modular forwarder superstructure for the dendromass transport. Proceedings of the $22^{\text {nd }}$ International Scientific on Conference “Transport Means 2018”, 2018, Trasalis-Trakai, Lithuania, 2018, pp. 537-541.

[2] Kašpárek J., Škopán M., Jonák M., Pokorný P. Experimental verification of FEM analysis of the forestry forwarder. Proceedings of the $20^{\text {th }}$ International Scientific on Conference "Transport Means 2016", 2016, Juodkrante, Lithuania, pp. 751-755.

[3] Shegelman I., Budnik P., Baklagin V. Simulation modeling of truck load of skidding tractors with a grapple for chokerless skidding. Croetial Journal of Forest Engineering, vol. 40, no. 2, 297-310.

[4] Nikooy M., Ahrari S., Saleri A., Naghdi R. Effects of rubber-tired skidder and farm tractor on physical properties of soil in plantation areas in the north of Iran. Journal of Forest Science, vol. 61, 2015, pp. 393-398.

[5] Yin Ch., Sun Q., Wu J., Liu Ch., Gao J. Development of electrohydraulic steering control system of tractor automatic navigation. Journal of Electrical and Computer Engineering, vol. 2018, 2018, $7 \mathrm{p}$.

[6] Wasilewski J., Kuranc A., Szyszlak-Barglowicz J., Stoma M., Slowik T., Barta D. Assessment of efficiency of an agricultural tractor engine for different rotational speeds. Proceedings of IX International Scientific Symposium "Farm Machinery and Processes Management in Sustainable Agriculture", 2017, Lublin, Poland, 2017, pp. 406-410.

[7] Bajla J., Bronček J., Antala J., Sekerešová D. Mechanical Engineering Tables (In Slovak). Selection Standards. Slovak Office of Standards, Metrology and Testing, 2014.

[8] Fabian P., Gerlici J., Masek J., Marton P. Versatile, efficient and long wagon for intermodal transport in Europe. Komunikacie, vol. 15, no. 2, 2013, pp. 118-123.

[9] Fomin O., Gerlici J., Gorbunov M., Lovksa A., Kravchenko K., Burlutski O., Lack T. Study into improvement of the hatch covers of general-purpose open wagons to provide strength under operational loading diagrams. Communications - Scientific Letters of the University of Zilina, vol. 21, no. 2, 2019, pp. 44-49.

[10] Fomin O., Gerlici J., Lovskaya A., Gorbunov M., Kravchenko K., Prokopenko P., Lack T. dynamic loading of the tank container on a flat wagon considering fittings displacement relating to the stops. MATEC Web of Conferences, vol. 234, 2018, 5 p. 